\title{
PSYCHOLOGISTS IN ITALIAN HOSPITAL SETTINGS: AN EXPLORATORY ANALYSIS OF HOSPITAL PHYSICIANS' REPRESENTATIONS AND DEMANDS OF PSYCHOLOGICAL INTERVENTION
}

\author{
Manuela Tomal ${ }^{*}$, Francesca Esposito** and Veronica Rosa*** \\ *PhD Assistant Professor at the Department of Dynamic and Clinical Psychology, Sapienza University of Rome, Italy. \\ E-Mail: manuela.tomai@uniroma1.it \\ ${ }^{* * P h D}$ Candidate at the ISPA - University Institute, Lisbon, Portugal. E-Mail: fesposito@ispa.pt \\ ${ }^{* * *}$ PhD Adjunct Professor at the Department of Dynamic and Clinical Psychology, Sapienza University of Rome, Italy. \\ E-Mail: veronica.rosa@uniroma1.it
}

\section{RESUMEN}

Aunque la Organización Mundial de la Salud ha evidenciado la importancia de adoptar modelos integrados de asistencia basados en el enfoque bio-psico-social, en los servicios de salud, como los hospitales, existe todavía mucha resistencia para su implementación. Se presenta un estudio exploratorio cualitativo dirigido a comprender las representaciones y las demandas de los médicos hospitalarios con respecto a la intervención psicológica en los contextos hospitalarios italianos. Conforme a este objetivo se desarrolló un guión de entrevista semi-estructurada y se entrevistaron 15 médicos italianos divididos por género, edad y especialidad médica. Fueron investigados las representaciones de la enfermedad, el acercamiento a los pacientes y los modelos de intervención, la experiencia de colaboración con psicólogos, las representaciones de dónde, cuándo y cómo los psicólogos podrían ser útiles en el contexto hospitalario, las visiones generales del hospital y de su futuro, los puntos de fuerza y de debilidad de su trabajo, las estrategias utilizadas para superar las dificultades diarias y las estrategias propuestas para mejorar el sistema hospitalario. El análisis de contenido de las entrevistas ha revelado que la intervención psicológica está representada predominantemente como una intervención a nivel in- dividual dirigida a contener el distrés emocional en relación con la enfermedad. Además se ha evidenciado la falta de consideración de la competencia psicológica como útil para promocionar el funcionamiento organizativo de los servicios hospitalarios. Estos resultados pueden apoyar la investigación futura en esta área y son utilizados para discutir las oportunidades de un diálogo constructivo entre ciencias médica y psicológica en los contextos hospitalarios.

Palabras clave: Competencia psicológica; Intervención psicológica; Contextos hospitalarios; Médicos hospitalarios; Representaciones; Demandas.

\section{ABSTRACT}

During the years, the World Health Organization has been emphasising the importance of promoting integrated models of care consistent with a bio-psycho-social approach to health-illness. Nonetheless, healthcare services still show much resistance to the implementation of such models and the use of multidisciplinary teams. As a consequence, and despite the efforts made over the years by psychologists, the role and specificity of psychological competence in healthcare settings 
continues to remain unclear. This is particularly true as regards hospital settings. Based on these considerations, this article presents an exploratory qualitative study aimed at understanding hospital physicians' representations of, and demands for, psychological intervention in Italian hospital settings. The main argument on which the study was based is that the integration of psychological competence into hospital settings very much depends on other professionals' representation of the psychological profession, as well as on the emotional symbolization of their work context and professional practice. A key role is played by physicians, whose representations of the psychological intervention in hospital settings have been under studied at the international level, and almost not studied with regard to the Italian context. The purpose of this study was to respond to this gap in the literature. In this regard, a semi-structured interview script was developed and used to interview 15 Italian hospital physicians varying in gender, age, and medical speciality. Participants were selected by convenience and interviews were carried out individually in the hospital settings. Representations of disease; approach to patients and models of intervention; experiences of collaboration with psychologists; representations of where, when and how psychologists could be useful in the hospital context; overall visions of one's hospital and its future; strengths and weaknesses of one's own work; strategies used to overcome everyday difficulties and strategies advocated to improve the hospital were focus of analysis. The interviews, administered by two researchers, were audio-recorded and transcribed. Then a content analysis was developed by three analysts that coded the units of the text (sequences) according to the categories and subcategories identified. The categories were: (a) perspective on medical intervention; (b) problems and weaknesses; (c) strengths; (d) current and future strategies; (e) psychosocial component of disease, and (f) relationship between Medicine and Psychology. Transcripts were analyzed independently by the analysts, and the interrater agreement was $83 \%$. Results revealed a widespread view that psychological science is of limited relevance in the hospital context. The difficulty in perceiving psychologists as a medical resource appeared to be largely related to physicians' endorsement of a bio-medical approach, as well as to their lack of opportunities for formal and/or informal collaboration with psychologists. Psychologists were thought of primarily as diagnosticians or therapists, and psychological intervention was mainly characterized as an individuallevel intervention whose main objective is to support the patient and manage his / her emotional response to the disease (and the response of his / her family). Despite physicians felt the hospital system plagued by problems, especially at the structural and functional levels, they did not envisage psychological competence as useful for fostering hospital organisational functioning. On the contrary, they advocated a top-down change in the hospital system, delegating responsibility for change to hospital management or policy makers. As a consequence, an urgent demand for Psychology remains unexpressed. Although based on a small sample, the present study provides useful insights which may prompt further research in this area. Furthermore, it provides information about the demand for psychological intervention in the hospital context which can be used to develop strategies to promote multidisciplinary care and integrated mind-body interventions. Results suggest the necessity to rethink professional roles and to promote a constructive dialogue between medical and psychological science in Italian hospital settings.

Key words: Psychological competence; Hospital settings; Hospital physicians; Representations; Demands.

\section{INTRODUCTION}

For several years the World Health Organization (WHO, 2000) has been emphasising the importance of promoting integrated models of care consistent with a biopsychosocial approach to health-illness (Engel, 1977). At present the international healthcare agenda is shaped by the increase in chronic diseases which result in complex needs. As a consequence, there is a requirement for new models of care which integrate different profes- 
sional competences and take advantage of synergisms among them (Axelsson, R., Axelsson, S., Gustafsson, \& Seemann, 2014; Dükers, Wagner, Vos, \& Groenewegen, 2011). At the European level, the European Parliament has encouraged the development and monitoring of health programmes centred on interdisciplinary teams [Resolution of 14 March 2012 on addressing the EU diabetes epidemic (2011/2911(RSP))]. Moreover, there is a substantial body of evidence that service users and their caregivers prefer integrated care provided by multidisciplinary teams to standard services (e.g., Rummery, 2009; Wong, Ho, Yeung, Tam, \& Chow, 2011), that multidisciplinary teams provide higher quality of care at lower cost (e.g., Sierra Murguía, 2013; Weeks et al., 2010), and that integrated systems often perform better than the fragmented forms of care that predominate (Shih et al., 2008).

Integrated models of care are, however, still not completely accepted within health services, and when they are adopted, they do not always result in detectable changes in the interaction between physicians and other health professionals (Burns \& Pauly, 2002; Waisberg, Veronez, Tavano, \& Pimentel, 2008).

Changes introduced to the health system during the 1920s in the United States, and subsequently in Europe and in other parts of the world, have facilitated the integration of psychological science into the hospital context (Wright \& Friedman, 1991). However, even today, in many countries only a minority of patients receive integrated mind-body interventions (Astin, Shapiro, Eisenberg, \& Forys, 2003; Wolsko, Eisenberg, Davis, \& Phillips, 2004). In Italy, the condition of development and integration of Psychology in healthcare settings appears particularly critical and complex. The lack of attention to psychosocial health in Italian medical training programs and medical contexts has been highlighted by several authors (Carli, 2013a, 2013b; Clerici \& Veneroni, 2014; Imbasciati, 2008). Furthermore, multidisciplinary teams are rare in Italian healthcare services, and do not necessarily include a psychologist.

Historical and cultural conditions in Italy are largely responsible for the neglected state of
Psychology. In 1923 Psychology was abrogated as a teaching discipline (Babini, 2009), and it was only in 1970 that the first undergraduate degree in Psychology was established.

As regards the healthcare system, the inclusion of Psychology occurred only in the late seventies beginning with community services. At that time Law n. 833 was enacted, providing for the presence of psychologists in mental health centers, family care centers, services for drug addiction (SERT), and district services (e.g., family services, services for people with a disability, elderly care services). In the hospital setting, psychologists entered about 10 years later, limited to highly qualified contexts of care and to rehabilitation services. Currently their presence is regulated by regional legislation. This gives rise to a very heterogeneous national scenario, with large differences between geographical areas. At present in Italy there is no national legislation concerning the role and functions of psychologists in the hospital setting.

In the 1978, the healthcare reform established in Italy a national health system of universalistic type. The consequent exponential increase in health spending favoured, in the following decades, the adoption of a business orientation to delivering healthcare. This led to a reductive and technicist use of the new organizational values, to a request to healthcare staff to increase their productivity in order to achieve efficiency criteria, and to disinvestment in variables considered non-essential or not immediately profitable (e.g., psychosocial ones). The introduction of a third dimension, the cost, substantially transformed the traditional physician-patient relationship (Carli, 2013a).

In all Western countries, the growth of managed care was accompanied by concern about the impact that changes in the healthcare organization would have had on the physicianpatient relationship (Alexander \& Lantos, 2006).

The formation of patient values, the patient autonomy and the physician divulging / dissemination / transmission of medical information have been key variables in many models of physician-patient interaction developed in 
the 90's. In the classification system proposed by Emanuel, E.J. and Emanuel, L.L. (1992), the interaction of these three variables produced four possible types of physician-patient relationship: paternalistic, deliberative, interpretive, or informative. The model created by Charles, Gafni, and Whelan (1999) pointed out that the combination of patient autonomy and information exchange is represented by a continuum, rather than by discrete points as argued by Emanuel, E.J. and Emanuel, L.L., (1992). Humphrey, Littlewood, and Kamps (1992) developed a model incorporating physician interaction style and patient coping abilities. Recent studies (Agarwal \& Murinson, 2012) have noted that key variables of the patient-physician interaction models are appropriate but sometimes fail to understand the potential independent expression of values and autonomy in individual patients because they are all coupled and change simultaneously. Nevertheless, the framework of Emanuel, E.J. and Emanuel, L.L. (1992), providing an useful taxonomy (Klein, 2012), is still the most widely adopted.

Over the last few decades technological advances in diagnostic and therapeutic practices, the efforts toward treatment standardization, the growing pressures for economic efficiency that lead to a faster consultation process make it lose the attention to the individuality of patients, and to their need for autonomy and information (Agarwal \& Murinson, 2012). Medical Anthropology scholars (e.g., Good, 2006) highlighted the increasing difficulty of physicians to listen to their patients, and capture in their words the essential elements for understanding and caring of the disease.

In opposition to this trend, at the beginning of the 20th century, the proposal from the Patient-Centered Medicine (Levenstein, Mc Cracken, McWhinney, Stewart \& Brown, 1986) first, and the narrative approach of Medical Anthropology (Charon, 2006; Charon \& Wyer, 2008), later, supported the idea that psychological competence (listening, empathy, and reflective thinking) can reduce the distance between physicians and their patients, considered in their complexity and uniqueness (Murphy, 2015). Being a relatively new ap- proach to the therapeutic relationship (especially in Italy), remain to be verified its feasibility in health contexts different from the AngloSaxon ones, where it has been developed (Clerici \& Veneroni, 2014).

In the Italian context, the opportunities for physicians and other hospital staff members to create an informed vision about the contribution of Psychology in healthcare settings, particularly in hospital ones, are limited. This evidence represents an obstacle to the implementation of integrated mind-body interventions.

\section{WHAT HINDERS THE IMPLEMENTATION OF MULTI- DISCIPLINARY WORKING IN A HEALTHCARE SETTING?}

In recent decades many researchers have analyzed the barriers to the implementation of multidisciplinary working in a healthcare setting, highlighting the importance of a variety of factors including structural factors, such as hospital management policies (Curry \& Ham, 2010), and group factors, such as team size and composition (Xyrichis \& Lowton, 2008), information sharing and communication (Burns, 2004), leadership (Ploeg, Davies, Edwards, Gifford, \& Miller, 2007), or capacity to share values, goals and practices among team members (Cubic, Mance, Turgesen, \& Lamanna, 2012). Recent research on the education and socialization of health professionals revealed that developing a professional identity in isolation from related professionals impedes the construction of an accurate representation of their competence (Khalili, Hall, \& DeLuca, 2014). In general, the emphasis on specialization of knowledge and skills, which characterizes the training of medical, and health professionals, as well as its separation from other specialties or related professional areas, promotes the development of a professional identity that some authors have defined as uniprofessional (Khalili, Orchard, Laschinger, \& Farah, 2013). This isolationist identity creates, as a result, a lack of understanding of the roles and perspectives of other professionals, and is considered to be one of the main barriers to 
interprofessional collaboration (Khalili et al., 2014).

Ignorance about the specific expertise of psychologists on the part of professionals in related areas, such as Medicine, adds to the confusion and uncertainty surrounding social representation of the specialism. Social representations constitute a spontaneous form of social knowledge that originates from personal experiences and cultural dimensions in which the individual is immersed (Moscovici, 1988); they allow the interpretation of reality, giving meaning to events and guiding actions. Social representation theory (SRT) (Moscovici, 1988) offers a framework to understand how groups of people communicate about and make sense of emerging or novel phenomena. In this view, social representations shape interactions within a community or organisation as well as the behavioral expectations that govern such exchanges (Moscovici, 1989). If it is true that it is a social mandate that allows the psychologist to work in a specific context, it is only the perceived necessity and usefulness of his / her competence in such a context that determines his / her intervention (Carli \& Salvatore, 2001). It means that changes at the macro level, whilst important, may not be sufficient to achieve organizational change (Curry \& Ham, 2010), unless they are supported by changes in representations of professionals' everyday practices. As a result, the integration of psychological competence into hospital settings and the realisation of the benefits it can offer very much depend on other healthcare professionals' (particularly physicians') representations of Psychology as a profession.

These considerations notwithstanding, research on physicians' representations of psychological interventions in hospital settings remains under-developed at international level, and almost non-existent in the Italian context. The extant research, much of which is rather dated, mostly focused on physicians' evaluations of the effectiveness of psychologists in hospital settings, the characteristics that a psychologist operating in a hospital setting should have, or the physician's perspective on factors that hinder or facilitate professional collaboration with psychologists. The evidence provided suggests that most physicians value the contribution of psychological services in the hospital context, with the percentage ranging from $71 \%$ (Nethercut \& Piccione, 1984) to 90\% (Schenkenberg, Peterson, Wood, \& Da Bell, 1981), and that they believe that psychologists who work in hospital settings should be reliable, friendly, empathic, helpful, and skilled in communications. A study conducted by Meyer-Probst, Roether and Wolfram (2002) found, however, that although the majority of physician endorsed the use of a holistic, interdisciplinary approach (integrating medical and psychological expertise), only one in five $(19.2 \%)$ had practised in this way at the beginning of his / her professional career owing to the nature of medical education. Physicians identified three main barriers to professional collaboration with psychologists (Kainz, 2002; Goldsmith, Wittenberg-Lyles, Rodriguez, \& Sanchez-Reilly, 2010); these concerned the time pressure under which medical consultations and interventions are carried out in hospital settings (e.g., need for emergency treatment), the lack of understanding of the objectives and techniques used in psychological intervention (e.g., uncertainty about the boundary between Psychology and Psychiatry), and the differences in professional cultures and related problems in com- munication.

Based on the above-mentioned considerations, and in order to promote a better integration of medical and psychological practice, the present study aims to study physicians' representations of psychological intervention in the Italian hospital context. In particular, the exploration of physicians' representations was conceived in terms of the study of the collusive dynamics operating in healthcare organizations. According to the analysis of the demand, a psychological theory and methodology of intervention developed by Carli and Paniccia (2003) in consulting work for organizations, the term collusive dynamics indicates

"the emotional symbolization of the context socially shared by those who belong to it" (Carli, Paniccia, Giovagnoli, Carbone, \& Bucci, 2015, p. 112). 
Through the emotional symbolization of the context one activates an emotionally engaging relational mode that is a source of implication not only at the level of emotional imagination, but also in terms of adaptive action (Carli \& Giovagnoli, 2011) According to this framework, exploring physicians' emotional symbolization of their work context (i.e., hospital setting) and professional practice, also in relation to that of psychologists (or the intervention they imagine psychologists may conduct), can provide insights about the particular demand that physicians require of psychology, highlighting areas of possible application of the psychological competence in the hospital context.

This study is the first attempt to explore such issues in the Italian context.

\section{MethOD}

To explore hospital physicians' views and demands concerning the psychological function within hospitals, a semi-structured interview protocol was created. The interview explored hospital physicians' views about the following topics: representation of disease; approach to patients and models of intervention; experiences of collaboration with psychologists; representations of where, when and how psychologists could be useful in the hospital context; overall visions of one's hospital and its future; strengths and weaknesses of one's own work; strategies used to overcome everyday difficulties and strategies advocated to improve the hospital. The semi-structured interview is particularly suited to small-sample research, indeed the format enables collection of rich, unexpected data. In-depth analyses of such data can reveal unexpected findings and help to clarify the links between cognitive, emotional, and behavioral perspectives on the phenomenon of interest (Cardano, 2003).

\section{PARTICIPANTS}

Individual semi-structured interviews were conducted with 15 physicians employed in hospitals located in central Italy. The study was limited to the 11 hospitals that gave their permission to carry out research activities. Participants were selected through convenience sampling, considering the heterogeneity of their medical specialty as a criterion. This criterion has been chosen not to discuss the impact that the different specialties have on the individual physicians' representations of psychological practice in hospital settings, but to ensure a greater richness and complexity of viewpoints. Heterogeneity sampling (also known as maximum variation sampling) is hence used by researchers when they seek a wide range of views about a topic of interest, or want to look at a phenomenon from different angles (Cohen \& Crabtree, 2006; Patton, 2002). Physicians with less than one year of professional experience were excluded. Participants varied in gender $(M=11 ; F=4)$, age (age range: $26-81$ years; $M=45.9 ; S D=14.4$ ), medical specialty, and years in professional practice (range: $1-50$ years; $M=15.7 ; S D=13.7$ ) (see Table 1 ).

\section{PROCEDURE AND COLLECTION OF DATA}

Individual face-to-face interviews with hospital physicians were conducted at the hospitals' facilities by two members of the research team. Each interview took an average duration of half an hour. During the interview the order of the topics was flexible according to the participant's narrative flow. All participants gave their written informed consent, after having received detailed explanations about the study aims and procedures (e.g., criteria of confidentiality), and had the possibility to ask questions. Interviews were digitally recorded for better accuracy and transcribed verbatim. All research procedures used in the study were approved by the Ethical Commission of the Department of Dynamic and Clinic Psychology of the Sapienza University of Rome.

\section{ANALYSIS}

A content analysis, according to Losito (2007), was performed. Content analysis is used in many fields of psychological research, 
such as clinical, health, and organizational. In particular, content analysis is used in exploratory research for bringing to light new insights and reveal the complexity of phenomena. This technique helps to reduce a large body of qualitative information

"to a smaller and more manageable form of representation” (Smith, 2000, p. 314).

Unlike other techniques of qualitative data analysis, it also allows the transformation of qualitative information into quantitative one, such as category frequencies or ratings (Smith, 2000). Being suitable for studying phenomena that are little explored or of which exist a fragmented knowledge (Losito, 2007), we opted for the use of content analysis in our study. The risk of excessive subjectivity and researcher bias, as well as of data fragmentation are both present in the analysis conducted with this technique. In our study we tried to limit these risks by involving three analysts in the coding process, as well as by using an ecological framework to enhance the connection between the several aspects (categories and subcategories) emerged during the analysis.

The unit of meaning or sequence was used as the unit of analysis (Trentini, 2001). In this context sequences are defined as narrative units that tell a complete thought, and whose alternation coincides with a change in the subject or direct object of the action, place, time, narrative mode, topic of discourse or specific aspects of same (Marchi, 1989). Sequences vary in length and may end with any form of punctuation. Sequences which consisted of information about gender, age, professional specialization or work experience; repetitions or partial repetitions of interviewer questions; requests to repeat or clarify questions; negative responses to interviewer requests for additional information or clarification were un-coded. Three analysts, members of the research team, took on the responsibility for the coding process. The analysts compared, discussed and clarified the meaning of the categories and subcategories identified until there was consensus on a final coding framework. Then, the transcripts were independently coded by the analysts. There was an $83 \%$ inter-rater agreement. In case of disagreement, the majority prevailed among the coders.

\section{RESULTS AND DISCUSSION}

The presentation of results is organized according to the categories and subcategories identified. For each of them the number of relative sequences are reported in order to highlight their relevance. Relevant quotations are also reported.

\section{Perspective on medical intervention}

This category included 114 sequences related to the understandings of the goals of medical intervention and practices, the procedures used in medical interventions; the physician's role; the relationships with patients, colleagues, and other professionals, the role of patient values and the conception of patient autonomy.

Among our participants, emerged two physician-patient relationship models very similar to those called informative (49 sequences, $43 \%$ ) and paternalistic (47 sequences, $41.2 \%$ ) in the classification system proposed by Emanuel, E.J. and Emanuel, L.L. (1992). These models appeared very frequently in the interview transcripts.

According to the authors, in the informative scenario the patient is characterized by well formed values and high autonomy, and the physician functions as a conduit of all relevant medical information. In our participants' narratives emerged an intervention approach based exclusively on clinical / organic data, and not open to considering patients' subjective meanings and values. Within this approach, the physician was represented as a technical expert, and the character of the physician-patient relationship was determined by the physician's competence in his / her area of expertise, as well as by his / her ability to provide truthful factual information (quote 1).

Emanuel, E.J. and Emanuel, L.L. described the paternalistic model as a situation in which the patient has poorly formed values 
regarding the medical situation. The physician independently decides the interventions to be taken, providing the patient with minimal medical information. Among our participants we identified an intervention model based on the physician's power and authority, where the physician-patient relationship was grounded on physician's a priori trust and reliability (quote 2). In this model the physician acted as a patient's guardian, discerning what was best for his / her health with limited patient participation and autonomy.

In the interpretive model, the patient has inchoate values regarding the situation, and the physician act mainly as a counselor (Emanuel, E.J. \& Emanuel, L.L., 1992). A small number of references in our interviews seemed consistent with the interpretive scenario (18 sequences, $15.8 \%$ ) (quote 3 ). In this medical intervention the physician wanted to know the values and characteristics of the patient, and helped the patient to understand his / her condition and values, as well as to choose the treatment that best suit to his / her case.

Finally, the deliberative model, which refers to an intervention approach where the patient has minimally formed values, and the physician works with him / her to discover these values, and to formulate an health-related decision, was not mentioned by our interviews.

If the patient already knows and has understood his disease... he should be instructed on the different treatment options that the Medicine may provide, for example, "A new drug is coming out on the market.... we have the opportunity to insert you into a clinical trial..." (quote 1). We follow the patient for through the entire journey... this makes you truly a reference: this is what I like, to be a point of reference for someone (quote 2). It is always important to understand a little bit about who is in front of you, otherwise we are faced with a clinical picture without the person (quote 3 ).

\section{PROBLEMS AND WEAKNESSES}

This category included 154 sequences in which physicians reported obstacles to good practice, gaps in care and other problems related to their work.
The problems and challenges facing the medical profession were many and diverse according to the participants. Problems in the strategic and structural dimension (concerning the political, legal, economic, and architectural levels) (58 sequences, 37.7\%) were mainly related to the political and economic management of the hospital (e.g., lack or mismanagement of funds and lack of meritocracy), and were mentioned with reference to their impact on physicians' contracts of employment, patient care and hospital functioning in general (quote 1). Problems in the psycho-environmental dimension (concerning the personorganization fit, including the expectations and demands of both parties) (48 sequences, $31.2 \%$ ) included criticisms of hospital management and the leadership team (e.g., head physicians), as well as competition and conflicts with colleagues. Many physicians also referred to difficulties in communicating diagnoses and prognoses to patients, and their families and to problems with disease management. The legal risks faced by physicians were a crucial concern of participants and they described how this made them practice defensively (quote 2). The main problems in the functional dimension (concerning roles, functions, and activities through which the hospital deliver services) (33 sequences, 21.4\%) were excessive working hours, backbreaking shifts, having insufficient time to provide a highquality service, and the rigid nature of hospital protocols and roles (quote 3). Finally, in the psychodynamic dimension (concerning the unconscious representations of work settings, shared assumptions, beliefs, values, individual and group emotions that govern everyday life within hospital settings) (15 sequences, 9.7\%, eight physicians) (the subcategory with fewer sequences) the main barriers and weaknesses reported by participants were the social devaluation of the medical profession (quote 4), a sense of frustration and helplessness at not always being able to intervene effectively, and emotional difficulties in the relationships with the patients.

In practice in healthcare there is first the policy and then the sick... this is not good for the sick (quote 1). 
I try to simplify what I mean: the complaint is always around the corner (quote 2).

We work on quantity rather than quality and... this makes you run (quote 3 ).

Our profession is devaluated on a daily basis, for a guard of 24 hours I earn seven euros gross per hour... while a cleaning lady takes eight (quote 4).

\section{STRENGTHS}

This category included 32 sequences in which physicians mentioned resources, strengths, and positive aspects of their work.

Participants made far fewer references to strengths than problems and weaknesses (32 vs. 154 sequences) and most strengths were related to the psycho-environmental (18 sequences, $56.3 \%, 12$ physicians), or psychodynamic dimension (six sequences, 18.8\%, 12 physicians). These two dimensions were closely associated as patients' gratitude and a sense of competence derived from being able to solve patients' problems were regarded as the most important satisfaction of medical work (quote 1). Participants referred to several functional strengths (four sequences, 12.5\%, four physicians) including the way in which they managed their work, which often involved drawing on personal resources and the experience (quote 2). Economic benefits and opportunities for collaboration were cited as strategic and structural strengths (four sequences, $12.5 \%$, four physicians).

What is gratifying is to see a person who comes back, thanks you, is happy... you understand... she understands that you have done all you can. This is, in my opinion, the most important aspect of this work (quote 1).

... Very important. Every year that passes I see that I work better... experience is very important (quote 2).

\section{CURRENT AND FUtURE STRATEGIES}

This category included 58 sequences in which physicians reported their strategies for dealing with everyday problems (current strategies), and the strategies they advocated to improve their hospital (future strategies).

Participants current strategies for dealing with everyday problems (30 sequences) mostly involved personal engagement (20 sequences, $66.7 \%$ ), i.e., reliance on personal characteristics, resources and experience (quote 1). Some physicians complained (six sequences, 20\%) about the difficulties they have to face daily in their work without proposing any solution, whilst others mentioned collaboration with colleagues or other professionals (e.g., psychologist) as a resource. Some participants also reported a defensive attitude to practice (two sequences each, $6.7 \%$ ), making use of professional power and status to negate, avoid, or tackle problems. None of the physicians mentioned management solutions., i.e., solutions related to organizational, economic, or political changes in hospital management.

The pattern of references to future strategies for one's hospital (28 sequences) was different. Participants made criticisms similar to those regarding the current situation, but suggested management solutions (17 sequences, $60.7 \%$ ) involving substantial top-down change in the hospital system and changes at the political, economic and administrative levels. It was suggested that physicians should have a more strategic role in the hospital system, and that there should be changes to financial and human resource policies (quote 2 ). There were fewer references to complaints (four sequences, 14.3\%), collaboration (three sequences, $10.7 \%$ ) or to the use of a defensive attitude (two sequences, $7.1 \%$ ). It is worth noting that personal engagement was rarely mentioned in the context of future strategies (two sequences, 7.1\%, one physician).

It's everything. I mean... also because the experience especially within the surgery field is crucial, as in the medical field in general. Also because experience lets you solve problems that you've already faced and step by step you have figured out how to solve (quote 1).

Greatly restrict bureaucracy, give physicians more say, especially in the organisation of work. Physicians should also be involved in the administration system (quote 2 ). 


\section{PSYCHOSOCIAL COMPONENT OF DISEASE}

This category included 36 sequences in which physicians referred to the concepts of health and disease, reporting their perspective on the role of psychosocial factors.

Analysis revealed that the majority of the participants (23 sequences, 63.9\%) considered that psychosocial factors played a role in the onset of disease, often constituting the cause. However, they mainly focused on environmental factors and lifestyles, personality type and character (quote 1) or psycho-emotional factors associated with dermatological and cardiovascular diseases (quote 2). Some participants (seven sequences, 19.4\%) considered that psychosocial factors had an important influence on the course or outcome of disease, determining its consequences (quote 3 ), whilst others (two sequences, 5.6\%) focused on their influence on the therapeutic process and the management of the disease, particularly their role in determining people's attitude towards disease and adherence to treatment (quote 4). Finally, some physicians (four sequences, $11.1 \%$ ), considered that there was a disconnect between the biological and psychosocial dimensions, claiming that non-biological factors had no influence in the onset of disease. The comments of a participant were particularly striking. She argued that serious clinical pathologies, such as neoplasia were not influenced by psychosocial factors, insisting that only pathologies with less impact on people's quality of life can be influenced by them (quote 5).

Irascible, emotional, stressed patients... suffer from cardiovascular problems with greater frequency than the rest of the population (quote $1)$.

Our practical experience suggests that there is always a psycho-emotional component in everything related to cardiac events (quote 2)

Well, I specialise in the treatment of chronic inflammatory intestinal diseases, in which the mood of the patient is certainly an essential consideration in the management of the disease. You should consider that this is a disease that, until recent times, was considered psychosomatic... Then in reality it is not so, in the sense that those characteristics are probably the consequence and not the cause of the disease (quote 3).

There are therapies that can be tedious and it can be very important that you are able to communicate well with the patient, to explain why he should accept them, rather than just doing them (quote 4).

I do not know. In our diseases, no. I mean, it is not that you get breast cancer for this reason (quote 5).

\section{Relationship between Medicine and Psychology}

This category included 155 sequences in which physicians referred to past, present, and future relationships between medical and psychological science, e.g., previous experiences of working with psychologists and how this affected their opinion of the profession, representations of psychologists' competence, views about which hospital wards need psychologists, what psychologists' tasks and functions should be.

The overwhelming majority of references to actual or hypothetical psychological interventions in the hospital setting (78 sequences), in the $82.3 \%$ of the cases ( 65 sequences) described an intervention focused on the patient. Only three participants (four sequences, 5.1\%) referred to patient's family (quote 1) as beneficiaries of psychological intervention, and just two mentioned their relevance to healthcare professionals (four sequences, 5.1\%) (quote 2 ). Psychological interventions in relationships were mentioned only in five sequences $(6.3 \%)$, four referring to the physician-patient relationship, and one sequence to relationships between healthcare professionals (quote 3 ). It is worth noting that no physician mentioned a role for psychological expertise at the organizational level.

I have people with severe facial malformations and, therefore, psychological support is needed both for them and for their families (quote 1).

But here there are physicians and nurses who do a difficult job... No one thinks about them (quote 2). 
The remedies might be... a psychologist who speaks with both nurses and physicians and tries to re-establish... a little trust between physician and patient, and between colleague and colleague (quote 3 ).

Various types of psychological intervention were mentioned (60 sequences). Most references to interventions with patients (48 sequences) concerned interventions with a supportive function (28 sequences, 58.3\%), i.e., management of the disease and the patient's emotional response to it. Some participants also mentioned the psychologist's role in facilitating the adaptation to and acceptance of the disease (nine sequences, $18.8 \%$, five physicians), psychological evaluation (five sequences, $10.4 \%$, three physicians), as well as in performing psychological evaluation (five sequences, $10.4 \%$, three physicians), i.e., diagnosis and assessment of mental functioning, and corrective interventions targeting dysfunctional behavior or beliefs (six sequences, $12.5 \%$, two physicians). The only references to interventions with a patient's family (three sequences) were to facilitating adaptation and acceptance of patient's disease (two physicians). References to interventions with healthcare professionals (four sequences) concerned the supportive function of psychologists in three cases, and their evaluative function in one case. References to interventions in relationships (five sequences) concerned mediation between physicians and patients (two sequences), psychological evaluation to establish the best approach to dealing with patients (one sequence), or corrective intervention in dysfunctional relationships, e.g., where trust between physician and patient has broken down (one sequence).

The professional relationship between physicians and psychologists (32 sequences) in the majority of cases was characterized by disconnected interventions, i.e., interventions made independently by physicians and psychologists without any collaboration or exchange of information other than case assignment (14 sequences, six physicians). Five participants mentioned episodic collaboration (seven sequences), usually with reference to the use of psychological evaluation to inform patient's medical management, which are considered as independent interventions (quote 1), and four participants spoke about cooperation (11 sequences), i.e., an integrated approach to all phases of patient care.

Look... he collects the history of the patient at the psychodynamic level, to see if there is some kind of psycho-emotional disorder, or psychiatric disorder that justifies the patient's attitude (quote 1).

The settings in which psychological expertise was felt to be most relevant were the oncology ward (10 participants), followed by surgery, pediatrics and neonatology (each one mentioned by five participants), and lastly the gynecology and the obstetrics (three participants). These wards were considered to have the psychologically weakest patients. It is noteworthy that 11 participants declared that they would like to have a psychologist attached to their own ward, whilst five participants considered it would be useful to employ a psychologist on all hospital wards.

\section{Conclusion}

Due to historical and cultural conditions, in Italy psychologists still struggle to define a clear, socially recognised role for the profession in the hospital context. Although international organisations, such as the WHO, and academics have long stressed the need for integrated models of care, an inability to transcend professional boundaries and the lack of attention to psychosocial aspects of health involve limited use of multidisciplinary teams in most Italian hospitals (Imbasciati, 2008). In this context, exploratory qualitative research into physicians' representations of psychological interventions in hospital settings provide important evidence, which can be used to develop strategies to promote multidisciplinary care and integrated mind-body interventions. Such data provide information about the demand for psychological interventions in the hospital context.

Content analysis of interviews with 15 Italian hospital physicians yielded evidence which was largely consistent with the extant litera- 
ture. There was a widespread view that psychological science was of limited relevance in the hospital context (Waisberg et al., 2008). Although our interviews provided evidence of high demand for psychological expertise, it remains the case that psychological intervention is characterized primarily, similar to the medical one, as an individual-level intervention (e.g., targeting the patient), whose main objective is to support patients and manage emotional responses to disease (including responses of patients' family). Psychological competence was not seen as useful in capturing the relationship between the individual and his / her environment. Such a representation also fails to acknowledge the role that Psychology can have in providing more complex and different readings of an organizational or social context. Physicians in our sample, did not value psychologists as experts in human relationships and individual-context interdependence, nor did they consider them competent to intervene at an organizational level. Psychologists were mainly viewed as diagnosticians or therapists (Carli, 2013a; Imbasciati, 2008).

Consistent with this image, the strategies used by physicians to handle the problems that plague the hospital system mainly rely on individual resources, rather than on contextual ones (e.g., colleagues and mental health professionals). Contrary to what literature pointed out, i.e., that mental disconnect and seeking social support are the strategies most used by physicians to cope with the demands and stressors of hospital work (see MartínezZaragoza et al., 2014), personal engagement was the strategy most commonly mentioned by our participants for addressing everyday problems. Conflicting relationships with colleagues and infrequent use of collaboration as a strategy to deal with critical issues suggest a lack of stress protective factors (FernándezAlcántara, García-Caro, Pérez-Marfil, \& Cruz-Quintana, 2013) in the healthcare settings considered in our study, and appear to confirm the presence of a lonely professional identity that fails to perceive the psychologist as a potential resource in conflict management and group processes (Landini, 2012).
Thinking about the future, the physicians in our sample advocated a top-down change in the hospital system, thus assuming a position of impotence and grievance, delegating responsibility for change to those at a higher level (hospital management or policy makers). Given that participants did not perceive themselves as potential agents of change in the hospital system, it is unsurprising that they did not envisage psychologists (whom they considered to have less power and lower status) in this role. So, an important and urgent demand for psychology remains unexpressed. On the contrary, psychological competence can potentially make a contribution within the physicianpatient relationship by providing counseling and advice to the consultant (the physician) and not only to the patient (Mannino, Mac Lennan \& Shore, 1975), or by training healthcare staff. In practice, the physicians of our sample did not perceive themselves as potential beneficiaries of psychological intervention.

The difficulty physicians have in perceiving psychologists as a medical resource seems to be largely related to their endorsement of a biomedical approach, and -in line with Allport's contact theory (1954)- to the lack of opportunities for formal and / or informal collaboration with psychologists (Schenkenberg et al., 1981).

According to previous studies (MeyerProbst et al., 2002), although most of the participants stressed the importance of psychosocial factors in the understanding and treatment of health problems, only a minority of them described an intervention consistent with an integrated approach (Astin et al., 2003). Moreover, the collaboration with psychologists was found to be episodic and uncommon. A representation of psychology as non-essential and substantially ancillary to medical science (Harris et al., 2013) may prevent the realization of the potential contribution of psychology to medical care. Further, the introduction of economic variables in the healthcare setting undermines the physician-patient relationship, devaluing the subjective and unique dimensions of the patient.

The proposal from the Patient-Centered Medicine (Levenstein et al., 1986), and later 
from the narrative Medicine (Charon, 2006; Charon \& Wyer, 2008), suggests significant changes in training systems and working practices of healthcare settings in English-speaking countries, supporting the idea that psychological competence can reduce the distance between the physician and the patient. Our data highlight the delay with which the Italian health system is incorporating such recommendations. Despite the demand for greater autonomy and control of patients over medical decision-making has continued to rise in recent decades, among our participants prevails a model of physician-patient relationship characterized by physician power and expertise, low patient autonomy, and distance between the two actors of the relationship. This model of relationship can affect patients' compliance and satisfaction, and result into a conflictual relationship between patients / citizens and health systems (expressed by the increase in patients' protests and complaints to the sick court) (Carli, 2013a; Rapporto PIT, 2011, 2012). This insight opens up new and interesting scenarios for the psychological profession.

Our data also appear to be consistent with the evidence provided by previous studies (Curry \& Ham, 2010), which have highlighted how changes at the macro level (e.g., legislation) should be accompanied by changes in the representation of professionals' everyday practices in order to be effective. This insight gives an indication for future interventions aimed at favouring the inclusion of psychologists in healthcare settings, and promote more efficient and integrated healthcare. In particular, we think that the promotion of joint training op- portunities for health professionals (physicians, nurses and psychologists), could provide an opportunity to create an adequate knowledge and representation of the contribution that the different professionals can respectively make towards the achievement of a common goal (promoting patients' health and wellbeing).

This study has also some limits. The sample for this pilot study was small and selected by convenience. This factor, combined with the uneven regional Italian scenarios, make our findings not representative of the national context. However, although partial, we believe that these results can prompt future research in this area. Indeed, to our knowledge, this study represents the first attempt to explore these issues in the Italian context, addressing a gap in the scientific literature. The result presented may also be used as a basis for the development of a quantitative instrument to explore attitudes and representations in a larger sample of hospital physicians, or of other hospital professionals (e.g., managers, nurses, social workers etc.).

When professional identities depend on a strong group identity, as in the hospital context, and when there are demands at national and international level for new and more complex care strategies, it is necessary to rethink professional roles and relationships (and by implication the relevant social representations which concern them) in order to deliver organizational change. We strongly believe that this is the direction to follow, and that scientific research can have a key role in this process providing important insights to conduct it. 
TABLE 1

PARTICIPANTS' CHARACTERISTICS

\begin{tabular}{|c|c|c|c|c|}
\hline Participants & Age & Gender & $\begin{array}{c}\text { Professional } \\
\text { experience } \\
\text { (years) }\end{array}$ & Medical speciality \\
\hline P1 & 41 & M & 8 & Dermatology \\
\hline $\mathrm{P} 2$ & 50 & M & 23 & Cardiology \\
\hline P3 & 53 & $\mathrm{~F}$ & 21 & Obstetrics and Gynaecology \\
\hline P4 & 35 & M & 11 & Obstetrics and Gynaecology \\
\hline P5 & 38 & M & 7 & General surgery \\
\hline P6 & 26 & $\mathrm{~F}$ & 1 & Oncology \\
\hline P7 & 37 & M & 5 & Respiratory physiology \\
\hline P8 & 81 & M & 50 & Anaesthesia and intensive care \\
\hline P9 & 64 & $\mathrm{~F}$ & 39 & Pulmonology \\
\hline P10 & 29 & M & 2 & Neurology \\
\hline P11 & 49 & M & 15 & Otolaryngology \\
\hline P12 & 43 & M & 12 & Gastroenterology \\
\hline $\mathrm{P} 13$ & 55 & M & 23 & Cardiology \\
\hline P14 & 34 & M & 9 & Maxillofacial surgery \\
\hline P15 & 54 & $\mathrm{~F}$ & 10 & Nephrology \\
\hline
\end{tabular}




\section{REFERENCES}

Agarwal, A.K. \& Murinson, B.B. (2012). New dimensions in patient-physician interaction: Values, autonomy, and medical information in the patient-centered clinical encounter. Rambam Maimonides Medical Journal, 3(3), e0017. http ://doi.org/10.5041/RMMJ.10085

Alexander, G.C. \& Lantos, J.D. (2006). The doctorpatient relationship in the post-managed care era. American Journal of Bioethics, 6(1), 29-32. http://dx.doi.org/10.1080/15265160500394556

Allport, G.W. (1954). The nature of prejudice. Cambridge, MA: Perseus Books.

Astin, J.A., Shapiro, S.L., Eisenberg, D.M., \& Forys, K.L. (2003). Mind-body medicine: State of the science, implications for practice. Journal of the American Board of Family Practice, 16, 131-147. http://dx.doi.org/10.3122/jabfm.16.2. 131.

Axelsson, R., Axelsson, S., Gustafsson, J., \& Seemann, J. (2014). Organizing integrated care in a university hospital: Application of a conceptual framework. International Journal of Integrated Care, 14(2). Retrieved december 13, 2014, from http://www.ijic.org/index.php/ijic/ar ticle/ view/ 1529/2412

Babini V.P. (2009). Liberi tutti. Manicomi e psichiatri in Italia: Una storia del '900 [Everybody free. Asylums and psychiatrists in Italy: A history of the '900]. Bologna: Il Mulino.

Burns, T. (2004). Community mental health teams: A guide to current practice. Oxford: Oxford University Press.

Burns, L.R. \& Pauly, M.V. (2002). Integrated delivery networks: A detour on the road to integrated health care? Health Affairs, 21, 128143. http://dx.doi.org/10.1377/hlthaff.21.4.128

Cardano, M. (2003). Tecniche di ricerca qualitativa [Techniques of qualitative research]. Roma: Carocci.
Carli, R. (2013a). Psicologia clinica e ospedale. Introduzione al tema [Clinical Psychology and hospital. Introduction to the topic]. Rivista di Psicologia Clinica, 1, 55-62.

Carli, R. (2013b). L'intervento psicologico in ospedale [Psychological intervention in hospital]. Rivista di Psicologia Clinica, 2, 3-11.

Carli, R. \& Giovagnoli, F. (2011). Psychoanalysis and analysis of the demand. In S. Salvatore \& T. Zittoun (Eds.), Cultural psychology and psychoanalysis: Pathways to synthesis (pp. 117-150). Charlotte, NC: Information Age Publishing.

Carli, R. \& Paniccia, R.M. (2003). Analisi della domanda. Teoria e intervento in psicologia clinica [Analysis of the demand. Theory and intervention in clinical psychology]. Bologna: Il Mulino.

Carli, R., Paniccia, R.M., Giovagnoli, F., Carbone, A., \& Bucci, F. (2015). Emotional textual analysis. In L.A. Jason \& D.S. Glenwick (Eds.), Hand-book of methodological approaches to community-based research: Qualitative, quantita-tive, and mixed methods (pp. 111-117). New York, NY: Oxford University Press.

Carli, R. \& Salvatore, S. (2001). L'immagine della Psicologia. Una ricerca sulla popolazione del Lazio [The image of Psychology. A study on the population of Lazio]. Roma: Kappa.

Charles, C., Gafni, A., \& Whelan, T. (1999). Decision-making in the physician-patient encounter: Revisiting the shared treatment decision-making model. Social Science \& Medicine, 49, 651-661. http://dx.doi.org/10.1016/S0277-95 36(99)00145-8

Charon, R. (2006). Narrative medicine: Honoring the stories of illness. New York, NY: Oxford University Press.

Charon, R. \& Wyer, P. (2008). Narrative evidence based medicine. Lancet, 371(9609), 296-297. http://dx.doi.org/10.1016/S0140-6736(08)601 56-7 
Clerici, C. A. \& Veneroni, L. (2014). La psicologia clinica in ospedale. Consulenza e modelli di intervento [Clinical psychology in the hospital. Counseling and intervention models]. Bologna: il Mulino.

Cohen, D. \& Crabtree B. (2006). Qualitative research guidelines project. Retrieved in December 13, 2014, from http://www.qualres.org/ind ex.html

Cubic, B., Mance, J., Turgesen, J.N., \& Lamanna, J.D. (2012). Interprofessional education: Preparing psychologists for success in integrated primary care. Journal of Clinical Psychology in Medical Settings, 19, 84-92. http://dx.doi.org/ 10.1007/s10880-011-9291-y

Curry, N. \& Ham, C. (2010). Clinical and service integration: The route to improved outcomes. London: The King's Found. Retrieved in June 7, 2014 from http://www.kingsfund.org.uk/sit es/ f iles/kf/Clinical-and-service-integrationNatash a-Curry-Chris-Ham-22-November-20 10. pdf

Dückers, M.L., Wagner, C., Vos, L., \& Groenewegen, P.P. (2011). Understanding organizational development, sustainability, and diffusion of innovations within hospitals participating in a multilevel quality collaborative. Implementation Science, 9, 6-18. http://dx.doi.org/10.11 86/1748-5908-6-18

Emanuel, E.J. \& Emanuel, L.L. (1992). Four models of the physician-patient relationship. Jama, 267(16), 2221-2226.

Engel, G.L. (1977). The need for a new medical model: A challenge for biomedicine. Science, 196(4286), 129-136. http://dx.doi.org/10.1126/ science. 847460

European Parliament (2012). European Parliament resolution of 14 March 2012 on addressing the EU diabetes epidemic (2011/2911(RSP)). Retrieved in september 21, 2015 from http://www. europarl.europa.eu/sides/getDoc.do?pubRef=-
//EP//TEXT+TA+P7-TA-2012-0082+0+DO $\mathrm{C}+\mathrm{XML}+\mathrm{V} 0 / / \mathrm{en}$

Fernández-Alcántara, M., García-Caro, M.P., Pérez-Marfil, M.N., \& Cruz-Quintana, F. (2013). Experiencias y obstáculos de los psicólogos en el acompañamiento de los procesos de fin de vida [Experiences and obstacles of psychologists in the accompaniment of end-of-life processes]. Anales de Psicología, 29(1), 1-8. http://dx.doi. org/ 10.6018/analesps.29.1.139121

Goldsmith, J., Wittenberg-Lyles, E., Rodriguez, D., \& Sanchez-Reilly, S. (2010). Interdisciplinary geriatric and palliative care team narratives: Collaboration practices and barriers. Qualitative Health Research, 20, 93-104. http://dx.doi.org/ 10.1177/1049732309355287

Good, J.B. (2006). Narrare la malattia. Lo sguardo antropologico sul rapporto medico-paziente [Narrating the disease. An anthropological perspective on the doctor-patient relationship]. Torino: Einaudi.

Harris, M., Greaves, F., Gunn, L., Patterson, S., Greenfield, G., Car, J., et al. (2013). Multidisciplinary integration in the context of integrated care - results from the North West London Integrated Care Pilot. International Journal of Integrated Care, 13. http://www.ncbi.nlm.nih. gov/pmc/articles/PMC3817952/

Humphrey, G.B., Littlewood, J.L., \& Kamps, W.A. (1992). Physician / patient communication: A model considering the interaction of physicians' therapeutic strategy and patients' coping style. Journal of Cancer Education, 7(2), 147-152. http://dx.doi.org/10.1080/08858199209528157

Imbasciati, A. (2008). La mente medica. Che significa umanizzazione della medicina? [The medical mind. What humanization of medicine means?]. Milano: Springer.

Kainz, K. (2002). Barriers and enhancements to physician-psychologist collaboration. Professional Psychology: Research and Practice, 33 
(2), 169-175. http://dx.doi.org/10.1037/07357028.33.2.169

Khalili, H., Hall, J., \& DeLuca, S. (2014). Historical analysis of professionalism in westernsocieties: Implications for interprofessional education and collaborative practice. Journal of Interprofessional Care, 28(2), 92-97. http://dx. doi.org/10.3109/13561820.2013.869197

Khalili, H., Orchard, C., Laschinger, H.K., \& Farah, R. (2013). An interprofessional socialization framework for developing an interprofessional identity among health professions students. Journal of Interprofessional Care, 27(6), 448-453. http://dx.doi.org/10.3109/13 561820.2013 .804042

Klein, E. (2012). Redefining the clinical relationship in the era of incentives. American Journal of Bioethics, 12, 26-27. http://dx.doi.org/10. 1080/15265161.2011.634487

Landini, F.P. (2012). Expectativas de los agentes de desarrollo rural argentinos sobre la Psicología y sobre la inserción profesional de los psicólogos en el ámbito de la extensión rural [Argentine rural development agents' expectations about Psychology and about the employ-ability of psychologists in the area of rural extension]. Interdisciplinaria, 29(2), 271286. http://dx.doi.org/0.16888/interd.2012.29. 2.10

Levenstein, J.H., Mc Cracken, E.C., Mc Whinney, I.R., Stewart, M.A., \& Brown, J.B. (1986). The patient-centred clinical method. 1. A model for the doctor-patient interaction in family medicine. Family Practice, 3(1), 24-30. http://dx. doi.org/10.1093/fampra/3.1.24

Losito, G. (2007). L'analisi del contenuto nella ricerca sociale [Content analysis in social research] (4th ed.). Milano: Franco Angeli.

Mannino, F.V., MacLennan, B.W., \& Shore, M.F. (1975). The practice of mental health consultation. New York: Gardener Press.
Marchi, A. (1989). Alla scoperta del testo narrativo [Discovering the narrative text]. Casale Monferrato (AL): Marietti Editore.

Martínez-Zaragoza, F., Benavides-Gil, G., AtoGarcía, M., Solanes-Puchol, A., Martín del-Río, B., Fernández-Castro, J., \& Pastor-Ruiz, Y. (2014). Predictors of distress in hospital physicians: Protective and vulnerability factors. Anales de Psicologia, 30(2), 579-587.

Meyer-Probst, B., Roether, D., \& Wolfram, C. (2002). Zum Stellenwert psychischer Faktoren in der ärztlichen Berufspraxis - Konsequenzen aus einer Ärztebefragung für die medizinpsychologische Lehre [About the importance of psychological factors in medical practice - Consequences for teaching in medicine from a survey of physicians]. Zeitschrift für Medizinische Psychologie,11(3), 139-143.

Moscovici, S. (1988). Notes towards a description of social representations. European Journal of Social Psychology, 18, 211-250. http://dx.doi. org/10.1002/ejsp.2420180303

Moscovici, S. (1989). Des représentations collectives aux représentations sociales: éléments pour une histoire. In D. Jodelet (Ed.), Les représentations sociales [Social representations] (pp. 62-86). Paris, France: Presses Universitaires de France.

Murphy, J.W. (2015). Primary health care and narrative medicine. The Permanente Journal, 19 (4), 90.

Nethercut, G. \& Piccione, A. (1984). The physician perspective of health psychologists in medical settings. Health Psychology, 3(2), 175-184. http://dx.doi.org/10.1037/0278-6133.3.2.175

Patton, M.Q. (2002). Designing qualitative studies. In M.Q. Patton (Ed.), Qualitative research and evaluation methods (3ra. ed.), pp. 230-247. Thousand Oaks: Sage.

Ploeg, J., Davies, B., Edwards, N., Gifford, W., \& Miller, P.E. (2007). Factors influencing best- 
practice guideline implementation: Lessons learned from administrators, nursing staff, and project leaders. Worldviews on Evidence-Based Nursing, 4(4), 210-219. http://dx.doi.org/10.11 1 1/j.1741-6787.2007.00106.x

XIV Rapporto PIT Salute. (2011). Diritti al taglio [Cutted rights]. Retrieved in August 10, 2015 from http://www.cittadinanzattiva.it/relazioniannuali/salute-1/rapporti-pit-salute.html

XV Rapporto PIT Salute. (2012). Servizio Sanitario Nazionale e Cittadini: Lo Stato (A) sociale [National Health Service and Citizens: The (A)Social State]. Retrieved in November 16, 2015 from http://www.cittadi nanza ttiva.it/ relazioni-annuali/salute-1/rapporti-pit-salute. $\mathrm{html}$

Rummery, K. (2009). Healthy partnerships, healthy citizens? An international review of partnerships in health and social care and patient/user outcomes. Social Science and Medicine, 69 (12), 1797-1804. http://dx.doi.org/10.1016/j.so cscimed.2009.09.004

Schenkenberg, T., Peterson, L., Wood, D., \& Da Bell, R. (1981). Psychological consultation/ liaison in a medical and neurological setting: Physicians' appraisal. Professional Psychology, 12(3), 309-317. http://dx.doi.org/10.1037/07357028.12.3.309

Shih, A., Davis, K., Shoenbaum, S. C., Gauthier, A., Nuzum, R., \& McCarthy D. (2008). Organising the U.S. Health Care Delivery System for High Performance. New York: The Commonwealth Fund.

Sierra Murguía, M.A. (2013). El rol del psicólogo en el equipo interdisciplinario de cirugía bariátrica [The role of the psychologist in bariatric surgery]. Interdisciplinaria, 30(2), 191-199. http://dx.doi.org/10.16888/interd.2013.30.2.1

Smith, C.P. (2000). Content analysis and narrative analysis. In H.T. Reis \& C.M. Judd (Eds.), Handbook of research methods in social and personality psychology. Cambridge: Cambridge University Press.

Trentini, G. (2001). Dalla formazione a distanza all'apprendimento in rete [From distance education to online learning]. Milano: Franco Angeli.

Waisberg, A.D., Veronez, F.D.S., Tavano, L.D. A., \& Pimentel, M.C. (2008). A atuação do psicólogo na Unidade de Internação de um hospital de reabilitação [The role of the psychologist at the admissions department of a rehabilitation hospital]. Psicologia Hospitalar, 6(1), 52-65. Retrieved in November 27, 2015 from http:// pepsic.bvsalud.org/scielo.php?pid $=\mathrm{S} 1677740$ 92008000100005\&script $=$ sci_ar ttext

Weeks, W.B., Gottleib, D.J., Nyweide, D.E., Sutherland, J.M., Bynum, J., Casalino, L.P., \& Fisher, E.S. (2010). Higher health care quality and bigger savings found at large multispecialty medical groups. Health Affairs, 29(5), 991-997. http://dx.doi.org/10.1377/hlthaff.2 009.0388

Wolsko, P.M., Eisenberg, D.M., Davis, R.B., \& Phillips, R.S. (2004). Use of mind-body medical therapies. Journal of General Internal Medicine, 19(1), 43-45. http://dx.doi.org/10.1111/j. 1525-1497.2004.21019.x

Wong, F.K., Ho, M. M., Yeung, S., Tam, S.K., \& Chow, S.K. (2011). Effects of a health-social partnership transitional program on hospital readmission: A randomized controlled trial. Social Science \& Medicine, 73(7), 960-969. http://dx.doi.org/10.1016/j.socscimed.2011.0 6.036

World Health Organization. (2000). The world health report 2000. Health systems: Improving performance. Geneva: World Health Organization. http://www.who.int/whr/2000/en/

Wrigth, L. \& Friedman, A. G. (1991). Challenge of the future: Psychologists in medical settings. In J.J. Sweet, R.H. Rozensky, \& S.M. Tovian (Eds.), Handbook of clinical psychology in 
medical settings (pp. 603-614). New York: Plenum Press.

Xyrichis, A. \& Lowton, K. (2008). What fosters or prevents interprofessional teamworking in primary and community care? A literature review. International Journal of Nursing Studies, 45(1), 140-153. http://dx.doi.org/10.016/j.ijnu rstu.2007.01.015

Department of Dynamic and Clinical Psychology Sapienza University of Rome Roma - Italy

Received: September 14, 2015 Accepted: August 25, 2016 